\title{
VIEWS OF OBSTETRICIANS AND PHYSIOTHERAPISTS ON ANTE-NATAL PREPARATION FOR CHILDBIRTH
}

\author{
B Fish; B Chalmers and D Meyer
}

\begin{abstract}
SUMMARY
Obstetricians' and physiotherapists' views of ante-natal childbirth preparation classes were examined by means of a postal questionnaire. Responses of 108 obstetricians and 57 physiotherapists revealed some marked differences in perceptions of childbirth classes offered by physiotherapists. In general physiotherapists' views were most favourable while obstetricians views were less so. Differences between physiotherapists' and obstetricians' views regarding the relevance of, and emphasis placed on, topics in childbirth preparation courses were also revealed. Data must, however, be viewed with caution due to the low response rate obtained.
\end{abstract}

\section{INTRODUCTION}

While much has been written on the historical rift that has developed between doctors and midwives over the past century or even longer ${ }^{1,2}$, few empirical studies appear to have been cönducted exploring the specific parameters of these differences. Studies by $\operatorname{Cogan}{ }^{3}$ and Hayward and Chalmers do șhed some light on' these issues but much still remains to be done to explore the possiblc differences of opinions that may exist between obstetricians and other professionals working in the area of childbirth.

The present study, initiated by the Obstetric Association of the South African Society of Physiotherapy, (OASASP) emerged as a result of perceived differences of opinions between obstetricians and physiotherapists regarding the value of ante-natal childbirth preparation classes.

Reports submitted to the OASASP from physiotherapists suggested that obstetricians were perceived as having somewhat negative views towards ante-natal preparation courses run by physiotherapists. Such perceptions were based on an apparent lack of support by obstetricians for their patients ${ }^{*}$ attendance at courses.

In consequence, a survey of the views of both obstetricians and physiotherapists towards physiotherapist run childbirth preparation classes was undertaken to ascertain the validity and extent of the perceived differences of opinion. It was hoped that possible problem areas regarding childbirth education courses would be highlighted by the survey as well as any perceived inadequacies in the preparation of couples for childbirth.

\section{PROCEDURE}

\section{Subjects:}

In total 527 questionnaires were mailed to obstetricians listed in the Medical and Dental Council register of South Africa, (Total $\mathbf{N}$ $=527$; TVL $\mathbf{N}=246 ;$ Cape $\mathbf{N}=162 ;$ Natal $\mathbf{N}=83$; OFS $\mathbf{N}=26$; Namibia $\mathbf{N}=5$;) and the Southern African Independent or Self Governing States or homeland areas $(\mathbf{N}=5$; Transkei $\mathbf{N}=2$; Kwazulu $\mathbf{N}=2$; Bophuthatswana $\mathbf{N}=21$ )

Initially approximately $15 \%$ of obstetricians completed ques-

\begin{abstract}
OPSOMMING
Die menings van verloskundiges en fisioterapeute ten opsigte van voorgeboorte klasse was deur middel van posvraelyste ondersoek. Vanuit die antwoorde van 108 verloskundiges en 57 fisioterapeute is verskeie sienswyses geopenbaar. In die algemeen is die fisioterapeute se menings meer gunstig daartoe. Verskille tussen die menings van verloskundiges ên. $\mathrm{fi}$ sioterapeute ten opsigte van die tersaaklikheid en klem van sekere onderwerpe in geboortevoorbereidingsklasse was ook gevind. As gevolg van die swak reaksie op viaelyste moet gegewens versigtig bekyk word.
\end{abstract}

tionnaires. A second copy of the questionnaire was then sent to a random sample of 250 of the non-responding obstetricians situated in major cities. Doctors residing in Namibia were not followed up as their numbers were few. In addition second questionnaires were not sent to obstetricians in Independent States, Self-governing States, rural or homeland areas as few if any physiotherapists were reported to be practicing in these areas. The second mailshot resulted in a total response rate from obstetricians of $20.5 \%(\mathrm{~N}=108)$. In addition 150 questionnaires were sent to all physiotherapists belonging to the Obstetric Branch of South African Physiotherapists (TVL $\mathbf{N}=\mathbf{9 3}$; Cape $\mathbf{N}=31$; Natal $\mathbf{N}=16$; OFS $\mathbf{N}=8$; Namibia $\mathbf{N}=2$ ). A $38 \%$ response to this appeal $(\mathbf{N}=57)$ was obtained. A second questionnaire was not sent to physiotherapists although a formal reminder and request to participate in the study was included in the newsletter of the Association.

\section{QUESTIONNAIRE}

Two equivalent questionnaires were developed for the obstetric and physiotherapy groups. Questions were phrased in such a way as to allow doctors' views of ante-natal childbirth education to be explored, as well as to tap physiotherapists' perceptions of obstetricians' views. Few items were open-ended: most supplied forced choice response items.

The questionnaire contained items relating to: biographical information; rates of referral to childbirth preparation classes or reasons for non-referral; existing patterns of communication between obstetricians and physiotherapists; the perceived impact of childbirth preparation classes on women's co-operation in labour; women's expectations of birth; and the perceived value and importance of various topics that could be included in childbirth preparation courses.

Questionnaire items were based on issues reported to the $\mathrm{Ob}$ stetric Association as reflecting a difference of opinion between obstetricians and physiotherapists as well as on items included in previous studies of childbirth preparation programmes'. Questionnaires were available in both English and Afrikaans. (Copies of the questionnaires are available from the authors.)

- Ms B Fish, BSc (Physiotherapy). Ante-Natal Educator, P O Box 735, Randpark Ridge 2156.

Prof B Chalmers* PhD. School of Psychology, University of the Witwatersrand, Johannesburg.

Dr D Meyer PhD. Department of Statistics, University of the Witwatersrand, Johannesburg.

*Address reprint requests to Prof B Chalmers, School of Psychology, University of the Witwatersrand, P O Wits 2050 South Africa. 


\section{Biographical Details}

In all, $45.3 \%$ of the obstetricians and $49.0 \%$ of the physiotherapists who completed questionnaires had been in practice for between 1 and 9 years. A further $25.9 \%$ of the obstetricians and $26.6 \%$ of the physiotherapists had been in practice for between 10-19 years, while the remainder $(26.8 \%$ of the obstetricians and $17.5 \%$ of the physiotherapists) had been in practice for more than 20 years. Very few (1.9\% of the obstetricians and $8.8 \%$ of the physiotherapists) had practiced for less than one year.

\section{Statistical Analyses}

The $\mathrm{x}^{2}$ likelihood ratio test was used for all analyses of differences between obstetric and physiotherapy groups.

\section{RESULTS}

\section{Response Rates}

The relatively low response rate, particularly of obstetricians (20.5\%) and to a lesser extent of physiotherapists (38\%), is detrimental to data interpretation. Findings of the study must therefore be viewed circumspectly. Of those who completed questionnaires, 77.8\% were English speaking and 22\% Afrikaans. It is not possible to report accurate numbers of English or Afrikaans speaking obstetricians or physiotherapists in the sample surveyed. If the language of the entry in the professional registers can be regarded as an indication of language distribution then $73 \%$ of the sample tested were English and $27 \%$ Afrikaans.

The poor response rate amongst Afrikaans speakers may be due to the poor quality of translation of the questionnaire into Afrikaans that unfortunately occurred. Procedural difficulties resulted in the questionnaires being mailed before errors of translation could be rectified. It is possible that results obtained reflect an English speaking professional view rather than being fully generalisable.

Alternatively, the paucity of Afrikaans responders may reflect some differences of opinion regarding the issues under examination in this language group. Further research is needed to clarify the reasons underlying the unequal representation of language groups amongst responders.

The majority of South African responders came from the Transvaal (47.2\%) with $25 \%$ responding from the Cape Province, $12.9 \%$ from Natal and $6.5 \%$ from the Orange Free State. These figures represent a response rate of $46.7 \%$ from the Transvaal mailing; $30.7 \%$ from the Cape lists; $15.7 \%$ from Natal and $4.9 \%$ from the OFS listings. Few respondents were obtained from Namibia (1.8\%), or $(0,9 \%$ or Namibians surveyed) or from Kwazulu $(0.9 \%),(0.4 \%$ Kwazulu response rate. No area of origin was given by $4.3 \%$ of the sample.

\begin{tabular}{|c|c|c|c|c|c|}
\hline \multirow{3}{*}{$\begin{array}{l}\text { Perceived } \\
\text { referral rates } \\
\text { of Primiparas by } \\
\text { Obstetricians } \\
\text { Physiotherapists }\end{array}$} & \multicolumn{2}{|c|}{$\begin{array}{l}\text { : Perceptions of of } \\
\text { fslotherapists of re }\end{array}$} & \multicolumn{2}{|c|}{$\begin{array}{l}\text { bstetricians and of } \\
\text { oferral rates }\end{array}$} & \multirow[b]{2}{*}{ Never } \\
\hline & $\begin{array}{l}\text { Frequer } \\
\text { Aways }\end{array}$ & $\begin{array}{l}\text { cy of Referral } \\
\text { Frequently }\end{array}$ & $\begin{array}{l}\text { I (\%) } \\
\text { Sometimes }\end{array}$ & $\begin{array}{l}\text { Hardly } \\
\text { ever }\end{array}$ & \\
\hline & $\begin{array}{l}41,7 \\
0,0\end{array}$ & $\begin{array}{l}36,1 \\
29,8\end{array}$ & $\begin{array}{l}12,0 \\
49,1\end{array}$ & $\begin{array}{l}3,7 \\
21,1\end{array}$ & $\begin{array}{l}6.5 \\
0,0\end{array}$ \\
\hline $\begin{array}{l}\text { Of Multiparas by } \\
\text { Obstetricians } \\
\text { Physiotherapists } \\
\text { Percentages do no } \\
\text { incomplete respons }\end{array}$ & $\begin{array}{l}13,9 \\
0,0 \\
\text { t alway } \\
\text { ses. }\end{array}$ & $\begin{array}{l}35,2 \\
5,3 \\
\text { otal } 100 \text { due }\end{array}$ & $\begin{array}{lr}35,2 & 8 \\
42,1 & 4 \\
\text { to one subjec }\end{array}$ & $\begin{array}{l}8,3 \\
43,9 \\
\text { ect's }\end{array}$ & $\begin{array}{l}6,5^{\circ} \\
8,8\end{array}$ \\
\hline
\end{tabular}

\section{Questionnaire Analyses}

One section of the questionnaire explored referral rates to ante-natal education classes. Obstetricians were asked about the number of patients they referred to classes while physiotherapists were asked what percentage of their patients were referred to them by doctors. As can be seen from Table 1 obstetricians report referring

both primiparous $(p, 001)$ and multiparous $(p, 001)$ patients for antenatal classes more often than physiotherapists perceive them to. $\left(\mathrm{X}^{2}\right.$ tests were performed by combining frequencies "always and frequently" and comparing these to the combined frequencies of "sometimes", "hardly ever" and "never". (Table 1).

In general views of obstetricians and physiotherapists towards the kind of ante-natal courses patients were referred to, seemed to concur. The majority of obstetricians $(68,5 \%)$ and physiotherapists $(70,2 \%)$ reported that patients were usually referred to classes offered by physiotherapists in private practice. These courses were preferred to those offered by midwives in private practice $(37,0 \%$ of obstetricians and $33,3 \%$ of physiotherapists). However, obstetricians do favour hospital based courses more than physiotherapists realised $(33,7 \%$ of obstetricians and $12,3 \%$ of physiotherapists (p). Of the obstetricians, $25,0 \%$ admitted to advising women not to attend classes on occasion. However, physiotherapists believed the non-referral rate of obstetricians to be in the region of $59.7 \%$.

Both groups were asked about obstetricians' reasons for not referring women to ante-natal childbirth classes. The most frequently reported reasons for non referral given by doctors were: that classes create unrealistic expectations of birth $(13,0 \%)$; that classes give inappropriate or even incorrect information $(13,0 \%)$ and that classes emphasize "natural birth" too much $(10,2 \%)$. Physiotherapists, however, believe that obstetricians do not refer their patients because they: don't know what ante natal classes offer $(47,4 \%)$; do not think classes are of value for multiparas $(36,8 \%)$; consider them to be an unnecessary financial burden for mothers $(26,3 \%)$; and consider that classes emphasize "natural birth" too much $(21,1 \%)$. As can be seen from Table 2, doctors' and physiotherapists' reasons for non-referral do not always coincide.

TABLE 2: Reasons for non-referral to antenatal classes.

As perceived by : (\%)
Reason for non-referral $\quad$ Obstetricians Physiotherapists

Classes create unrealistic

expectations of birth

Classes give inappropriate

or incorrect information

Classes emphasise "natural

birth" too much

Doctors do not know what

classes offer

multiparas

Classes are an unnecessary

financial burden

Classes are medically

inadvisable

Classes create unrealistic

expectations of Doctor's role
Classes not relevant for
13.0

1.9

6.5

5.6

6.5
Obstetricians and physiotherapists were further questioned about one of the reasons for non-referral, viz., that women emerge from classes with expectations of a "natural" birth. Answers to the question "Do you find that mothers who have attended ante-natal classes expect to have a natural/unassisted labour and birth?" revealed some difference between obstetricians and physiotherapists. Obstetricians reported this expectation as occurring in women $81 \%$ of the time at least frequently if not more often, while physiotherapists believed this to be so in only $67 \%$ of cases. (p) The majority of physiotherapists $(94.7 \%)$ also reported that they believed women to be more co-operative in labour if they had attended classes. Many physiotherapists (75\%) but significantly fewer obstetricians believed this to be the case (p). Doctors and physiotherapists appeared to agree, however, on the value of exercise in ante-natal preparation classes for normal pregnancies (90,7\% and $94,7 \%$ respectively).

The issue of communication between obstetricians and physiotherapists was also explored. Both doctors (75\%) and, to a significantly greater extent, physiotherapists $(91,2 \%)(p, 05)$, would 
like to have more communication with each other. However, $26,9 \%$ of obstetricians perceive physiotherapists as routinely requesting feedback or communication about patient referrals while $54.4 \%$ of the physiotherapists report a routine request for information

The idea that differences in perceived communication rates may be associated with obstetricians' referral to physiotherapists in general, rather than specifically for ante-natal education, was also explored. Altogether $79.6 \%$ of obstetricians reported referring patients to physiotherapists for reasons other than childbirth preparation. However only $59.7 \%$ of physiotherapists who take ante-natal classes report such referrals (p).

TABLE 3: Perceived importance and adequacy of coverage of topics included in childbirth preparation courses.

\begin{tabular}{ccc} 
Topics & $\begin{array}{c}\text { \% reporting } \\
\text { topic as } \\
\text { necessary }\end{array}$ & $\begin{array}{c}\% \text { regardinge } \\
\text { coverage as responding } \\
\text { adequate }\end{array}$ \\
\hline
\end{tabular}

Obstet Physio Obstet Physio Obstet Physio

\section{Pinysicai aspects:}

Anat/physiol of female $47.4^{\star} 100.0$

Anat/physiol of male 59.3100 .0

Breast care

Normal labour

$39.0^{*} 94.1$

$42.2^{4} 100.0$

Breech delivery

$51.9^{* * " 9} 92.3$

Pregnancy care:

Exercise

Diet

$42.7^{*} 100.0$

$64.1^{* *} 100.0$

$40.7 \quad 50.0$

$72.7^{*+*+1} 100.0$

$74.7^{\circ+*} 100.0$

$55.6 \quad 53.9$

78

27

77

90

$72.0^{* * * *} 100.0$

82 $45.8^{*} 94.1$

$50.0 \quad 64.7$

72

Medical Interventions:

Caesarean section

Forceps

Induction

$50.0^{4700} .0$

$66.7^{\text {atat }} 94.1$

57.8100 .0

$59.7^{*} 100.0$

Epidural/analgesia

Episiotomy

57.0 "100.0

$41.5^{*} 100.0$

$53.1^{* * * *} 88.2$

$49.3^{*} 100.0$

$57.0^{\text {s.m }} 94.1$

$70.7^{\text {tatk }} 100.0$

$41.0^{*} 100.0$

$72.3^{\text {natk }} 100.0$

Labour:

Pushing techniques $43.5^{\circ} 100.0$

Breathing techniques $37.4^{*} 100.0$

Pain

$76.1^{\text {ankt }} 100.0$

$82.4 \quad 100.0$

$43.3^{*} 100.0$

$74.4^{\text {ank }} 100.0$

\section{8}

64

67

79

82

83

92

91

90

Post Partum:

In hospital stay

Going home

Baby care

Infant Feeding:

Breast feeding

Bottle feeding

$54.4 \div 00.0$

$58.8^{* \star *} 88.2$

$63.8^{\text {*1" } \$ 4.1}$

$44.8^{\text {knt }} 82.4$

68

60.087 .5

$\begin{array}{ll}47.7 & 75.0\end{array}$

58

$39.0^{\circ} 100.0$

$68.8^{* \star * *} 100.0$

77

$38.3^{*} 100.0$

$68.3 \quad 73.3$

$50.7^{*} 100.0$

Fathers' role:
Role in labour

$75.0^{*} 100.0$

$\begin{array}{lll}61.6 & 94.1 \quad 73\end{array}$

$26.9^{\circ} \quad 53.3$

52

$41.7^{* *} 86.7$

60

experiences of labour $68.3 \% 100.0$

Psychological preparation:

For early parenthood 82.594 .1

$\begin{array}{llll}\text { For life style changes } & 71.6 \quad 94.1 \quad 32.8\end{array}$

$19.3^{*} \quad 82.4$

57

Significant difference with a P-value .001

" Significant difference with a P-value .01

Significant difference with a P-value .05

The final issue explored in the present study concerned the perceived adequacy of coverage given to a variety of possible child. birth education course topics and the perceived importance of these. Topics explored included physical aspects of pregnancy and birth: medical interventions commonly used; the hospital stay; psychological preparation of both mother and father, infant care and infant feeding; exercises; breathing; and other pain relieving techniques commonly used in labour. Table 3 reports the percentage of obstetricians and physiotherapists reporting that these topics are necessary in childbirth preparation courses, and the percentage reporting that they are being adequately covered at present. Onty the data from respondents who completed both aspects of this question were included in data analyses. Many physiotherapists responded to only one aspect of this question and these answers were, therefore, omitted from the anahysis.

It is of interest to note that while physiotherapists regard almost all the topics explored as necessary in childbirth education courses (range $=87.5 \%-100.0 \%$; Table 3 ) only about half of the obstetricians do so (range $=37.4 \%-82.5 \%$; Table 3 ). Similarly in most instances physiotherapists perceive their current coverage of these topics in classes to be adequate (range $=50.0 \%-100.0 \%$; Table 3) while fewer obstetricians perceive this to be so (range $=19.3 \%$ 82.4\%; Table 3). This trend is minimally reversed with regard to preparation for breech delivery.

Some of the education topics regarded by obstetricians as less necessary are of interest. These include preparation for episiotomy $(41,5 \%)$, shaving and enemas $(41,0 \%)$, exercise $(42,7 \%)$, breast care $(39,0 \%)$, breast feeding $(39,0 \%)$ and bottle feeding $(38,3 \%)$.

On the other hand, $82,5 \%$ of obstetricians regard preparation for early parenthood and $\mathbf{7 1 . 6 \%}$ for life style changes resulting from parenthood to be necessary. Of note is that while obstetricians perceive these topics to be poorly covered at present $(19,3 \%$ and $32,8 \%$ respectively) most physiotherapists perceive them to be well taught $(82,4 \%$ and $76,5 \%$, respectively)

Acknowledged by both groups as being fairly important and not well enough covered at present are topics relating to the father's psychological involvement in the process of transition to parenthood (Table 3).

As can be seen from Table 3, the most significant differences to emerge between obstetricians and physiotherapists regarding topics of importance for childbirth preparation courses related to the anatomy and physiology of women, viz. breast care, normal labour, exercise, diet, episiotomies, shaving and enemas, pushing, breathing and pain management techniques, infant feeding and the father's role in labour. In all instances obstetricians rated these topics as less important than physiotherapists did (p). Coverage of topics as presently adequate was also perceived significantly differently by obstetricians and physiotherapists in some instances. The most significant differences to emerge related to the coverage of induction as well as the psychological preparation of mothers for early parenthood and life style changes after birth, and for the preparation of fathers for their role as parents ( $\mathrm{p}$ ). In all instances obstetricians' ratings of the adequacy of coverage were lower than those of physiotherapists.

\section{DISCUSSION}

The tentative nature of any interpretations of the findings of this study must be emphasised. The obstetricians and physiotherapists studied, do however, appear to differ with regard to many of their views on current ante-natal preparation courses. To what extent these findings may apply to the population of physiotherapists and obstetricians in general, however, needs confirmation from future research.

The findings of the present study suggest that physiotherapists perceive obstetricians to refer patients to childbirth classes less often than doctors report they do. Perceived reasons for non-referral also differ with obstetricians appearing to be concerned about mothers developing unrealistic expectations about natural childbirth and gaining inaccurate information from classes. On the other hand, physiotherapists' primary reasons for obstetricians' non-referral appear to be a belief that doctors do not know what ante-natal classes actually offer. That at least one aspect of the obstetricians' fears seems to be realised, is supported by the finding that most women, as perceived by doctors $(\mathbf{9 4 , 5 \% )}$ and by physiotherapists $(86,0 \%)$, do show a desire for natural childbirth following classes. Whether this is due to the content of classes themselves is open to question, as women who go to classes may be those with a higher need for natural childbirth in the first place.

Obstetricians and physiotherapists do appear to agree on the need for greater communication: between them regarding patient care. It seems probable that such communication could facilitate a greater understanding between the professions regarding the place of childbirth education. 
There also appears to be agreement on the type of ante-natal preparation class to which obstetricians refer most often: in this case, physiotherapist run courses. While obstetricians do appear to support physiotherapist run childbirth preparation classes, they do have some very specific, clear criticisms of the services offered by them.

By far the greatest contrast between obstetricians' and physiotherapists' views appeared to occur with regard to the necessity and adequacy of coverage' of various topics usually included in childbirth preparation classes. Far fewer obstetricians than physiotherapists see the necessity for the majority of topics covered in classes. In addition fewer obstetricians see these topics as being adequately covered by existing preparation courses anyway. This underestimation of the value of topics on the part of obstetricians extends even to such topics as preparation for breast and bottle feeding as well as for almost routine but frequently disliked procedures ${ }^{6}$ associated with labour such as episiotomies, shaving and enemas.

While obstetricians appear to underestimate the need for preparation on a number of topics, physiotherapists appear to perceive their coverage of most topics as almost totally adequate. The main area to be acknowledged by both groups as reasonably important and not adequately covered in current classes are those relating to psychological preparation for parenthood and in particular to the father's involvement throughout his transition to parenthood.

The existence of such institutes as the International Childbirth Education Association based in the USA and the National Childbirth Trust based in the UK, suggests a need, at least on the part of mothers, for childbirth preparation courses. Open to question and currently receiving much attention, is the question of how best to approach the content and methods to be utilized in courses $7-21$. The efficiency of childbirth education courses, like many other aspects of medical and particularly obstetric care, is being questioned today ${ }^{2223}$. Further research is still needed to clarify what should be offered to parents-to-be, how it should be done and why. These questions

\section{Control Physio- therapist}

\section{Addington Hospital, Durban}

\section{Commencing salary R38 697 per annum plus a $10 \%$ non-pensionable allowance}

\section{Requirements: - Registration as a}

Physiotherapist with the SAMDC PLUS - At least seven years' appropriate experience.

Note: Applications must be submitted on form 2.83, obtainable from any Public Service department, and should be accompanied by certified copies of qualifications.

\section{Applications, stating reference} number 36067/326, to the Director General, Provincial Administration of Natal, Private Bag $\times 9037$.

Pietermaritzburg 3200.

Enquiries: $\mathrm{Mr} \mathrm{G}$. Minnie tel. [031] 32-2111 ext 660 .

\section{Closing date:}

30 May 1991

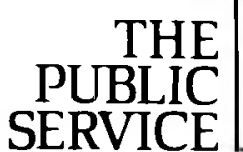

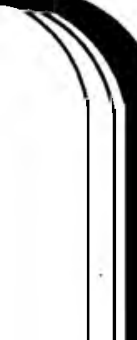

\section{.}

